\title{
Mean Pulmonary Arterial Pressure
}

National Cancer Institute

\section{Source}

National Cancer Institute. Mean Pulmonary Arterial Pressure. NCI Thesaurus. Code C120935.

The average blood pressure reading in the pulmonary artery as calculated through multiple cardiac cycles. 